\title{
Paget's Disease of the Vulva in Premenopausal Woman Treated with Only Surgery: A Case Report
}

\author{
Hamid Asmouki, ${ }^{1}$ Rachid Oumouloud, ${ }^{1}$ Abderrahim Aboulfalah, ${ }^{1}$ \\ Abderraouf Soummani, ${ }^{1}$ and Abdelouahed Marrat ${ }^{2}$ \\ ${ }^{1}$ Department of Obstetrics and Gynaecology, School of Medicine and Pharmacy, Mohammed VI University Hospital,
Cadi Ayyad University, Marrakech 40000, Morocco
${ }^{2}$ Al Fadle Histopathology Laboratory, Amitaf Residence, Avenue Yaacoub El Mansour, Appartment no. 5, Marrakech 40000, Morocco
}

Correspondence should be addressed to Hamid Asmouki, asmouki@gmail.com

Received 10 July 2012; Accepted 22 August 2012

Academic Editors: C. Gennatas, C. V. Reyes, and N. Yoshimura

Copyright (C) 2012 Hamid Asmouki et al. This is an open access article distributed under the Creative Commons Attribution License, which permits unrestricted use, distribution, and reproduction in any medium, provided the original work is properly cited.

Paget's disease of the vulva remains a rare condition with only a limited number of cases reported in the literature. It is an uncommon neoplasm usually of postmenopausal white women characterized by controversies in its prevalence, clinical features, treatment strategies, and prognostic. We here report a case of a primary Paget's disease of the vulva in premenopausal woman treated by only surgery with a favorable issue.

\section{Introduction}

In 1874, Sir James Paget published the first description of the disease, his original case was of disease involving the nipple and areola [1]. Fifteen years later (1889), Crocker reported extramammary Paget's disease affecting the scrotum and penis [2]. In 1901, Dubreuilh described the characteristic "cake-icing appearance" of vulvar Paget's disease [3]. This very rare malignancy is originating in vulvar apocrinegland bearing skin cells or as a manifestation of adjacent primary anal, rectal, or bladder adenocarcinoma [4]. It is an uncommon disease with incidence reports varying between $<1 \%$ and $2 \%$ of vulvar malignancies [5]. Paget's disease of the vulva (PDV) is commonly seen in postmenopausal Caucasian females; and appears clinically as red, eczematous, and pruriginous - and sometimes painful—lesions [6]. Surgery has been the treatment of choice, but because of the disappointing results of surgical treatment, many authors have been encouraged to try other procedures for PDV.

We will discuss the diagnostic features, treatment, and prognosis of this disease through the observation of a 43year-old woman with noninvasive PDV treated by only surgery.

\section{Case Presentation}

A 43-year-old nonmenopausal woman presented to department of dermatology with complaints of vulvar pruritus, painful vulvar lesion, and recurrent vaginal discharges, during one year.

She was treated with topical steroids and antimycotics. As there was no improvement with the above treatment, she was referred to department of obstetrics and gynecology.

On examination, patient had papular and erythematosquamous vulvar lesion extended to the labia majora and labia minora (Figure 1). Cervical exam was normal. Vulvar biopsy was taken, histopathological examination showed noninvasive PDV. The treatment was surgery with wide local resection and margin control by frozen section examination. No recurrence was seen during two years after treatment with disappearance of pain and improved quality of life.

\section{Discussion}

Paget's disease of the vulva (PDV) is a rare locally recurrent chronic disease, accounting for less than $1 \%$ of vulvar neoplasms [7]. The vulva remains the most frequently involved 


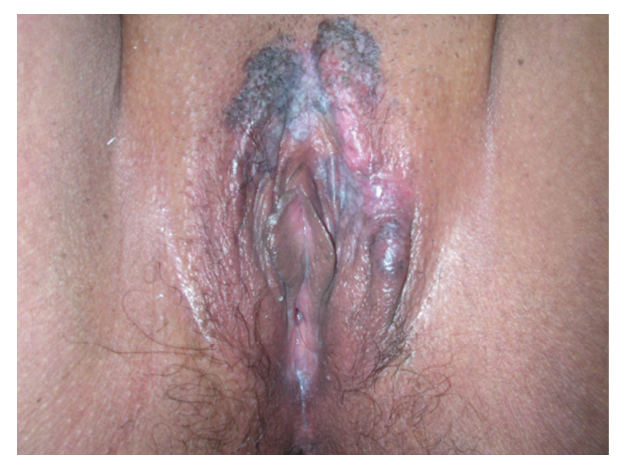

FIgURe 1: Macroscopic appearance of Paget's disease of the vulvaerythemato-squamous lesion extended to the labia majora and labia minora.

site with $65 \%$ of extramammary Paget's disease located in this area [8]. It occurs predominantly in postmenopausal Caucasian women [6]. The rarity of this disease has caused difficulties in its characterization. Controversies exist in the literature regarding its pathogenesis, the prevalence of concurrent underlying adenocarcinoma, associated malignancies, optimal treatment, and recurrence after surgical excision.

Concerning the pathogenesis, it is still the subject of great debate. Toker cells have been described as precursor cells of both mammary and extramammary Paget's disease. These cells are found in the basal layer of the epidermis and are adjacent to the lactiferous ducts in the nipple [9]. They also occur as a normal constituent of genital skin in association with mammary like glands of the vulva [10]. Another theory has been advanced, the concept that Paget cells are in fact malignant keratinocytes, which has been transformed in situ [11]. Current evidence supports the fact that angiogenesis plays an important role in the pathogenesis of PDV. However Ellis et al. [12] demonstrated that it is possible that in PDV, Paget cells can migrate and progress to invasive disease by utilizing the existing vasculature, without the need for the formation of new blood vessels.

Clinically, the lesions in PDV are non specific and multiple topical therapies are often tried before the diagnosis is made, a median delay of two years has been reported [5, 13]. It appears as a pink eczematoid area with white islands of hyperkeratosis that is accompanied by pruritus in $70 \%$ of patients [14]. A palpable mass should raise concern for underlying invasive disease. A classification system has been proposed by Wilkinson and Brown that divides vulvar Paget's disease into two groups, primary and secondary disease. Primary cutaneous Paget's disease is an intraepithelial adenocarcinoma arising within the epidermis or underlying skin appendages. Secondary or noncutaneous Paget's disease originates from an underlying noncutaneous adenocarcinoma, most commonly anorectal adenocarcinoma, and urothelial carcinoma of the bladder or urethra, carcinoma of the cervix, ovary, or endometrium [15]. The diagnostic is established by a biopsy, and immunohistochemical studies may be helpful in distinguishing primary and secondary lesions [16].
The usual treatment for PDV is surgical excision. Over the years, many therapeutic modalities have been attempted on patients with PDV in an effort to reduce the significant morbidity associated with the often-radical surgical treatments performed. In case of invasive PDV, wide partial or total vulvectomy with inguinal-femoral nodal assessment followed by chemotherapy or radiotherapy is advised. Because of the high recurrence rates ranging between $30-60 \%$ and attributed to subclinical extension and multifocal disease, margin status gained interest [17] with intraoperative frozen section analysis [18]. In our case, there was negative surgical margin which can explain absence of recurrence. Major controversy exists regarding the influence of surgical margins status on the recurrence rate. Some studies found that positive margins correlate with increased recurrence rate $[19,20]$. However, other studies have found no correlation between margin status and local recurrence [21-24]. The high frequency of recurrence, usually outside the area of previous resection, remains the most challenging feature in the management of vulvar intraepithelial Paget's disease. Long-term monitoring of patients is recommended, and repeat surgical excision is often necessary [24].

Alternative nonsurgical or combined treatments have been proposed, including radiotherapy, topical chemotherapy with intralesional interferon alfa-2b, laser ablation, photodynamic therapy, topical fluorouracil $(5-\mathrm{Fu})$, and imiquimod 5\% cream [25]. Radiotherapy has been used both as a definitive treatment as well as in the postoperative setting to prevent local recurrence. It should be used as an initial treatment mostly in selected patient groups (elderly, those unfit to undergo conventional surgery), as well as postsurgical treatment in positive surgical margins or recurrent disease [26]. While some state that radiation therapy produces poor results [27], others disagree [19, 28]. Laser treatment of PDV gained interest in the hopes that it would provide a conservative approach to eradicate the disease while preserving vulvar anatomy and sexual function. This procedure has been used successfully $[29,30]$, but has the disadvantage of significant postoperative pain and high recurrence rate $[19,31]$. Another option for clinical treatment of PDV, topical imiquimod 5\% cream seems to be promising [25]. Topical photodynamic therapy (PDT) offers an optional approach for extramammary Paget's disease. The complete clinical response rate to PDT at month 6, after two series of two illuminations, was equivalent to that for surgery. Although the recurrence rate was high, this treatment may be repeated without functional or physical consequences. PDT resulted in disappearance of pain and improved quality of life [32]. In invasive or noninvasive PDV, HER-2/neu protein is found to be overexpressed in $5 \%$ to $80 \%$ of cases. The availability and success of targeted therapies in the treatment of HER-2/neu positive breast cancer had led some authors to suggest its use in vulvar Paget's disease. Significant improvement of symptoms and significant reduction of vulvar Paget's lesion were reported in recurrent disease treated with Trastuzumab [33]. No adjuvant treatment was used in our case because of the favorable issue of the disease. 


\section{Conclusion}

Despite Paget's disease of the vulva has been described over 100 years ago, still remains a largely confusing and relatively rare disease. It is clear that randomized controlled trials are needed to adequately evaluate and compare therapeutic modalities, so that standardization may be attempted and initial treatment protocols elaborated to determine the best combination of greatest efficacy with least morbidity.

\section{References}

[1] J. Paget, "On disease of the mammary areola preceding cancer of the mammary gland," St Bartholomew's Hospital Research, vol. 10, article 87, 1874.

[2] H. R. Crocker, "Paget's disease affecting the scrotum and penis," Transactions of the Pathological Society of London, vol. 40, pp. 187-191, 1889.

[3] W. Dubreuilh, "Paget's disease of the vulva," British Journal of Dermatology, vol. 13, pp. 403-413, 1901.

[4] H. Niikura, H. Yoshida, K. Ito et al., "Paget's disease of the vulva: clinicopathologic study of type 1 cases treated at a single institution," International Journal of Gynecological Cancer, vol. 16, no. 3, pp. 1212-1215, 2006.

[5] I. S. C. Jones, A. Crandon, and K. Sanday, "Paget's disease of the vulva: diagnosis and follow-up key to management; a retrospective study of 50 cases from Queensland," Gynecologic Oncology, vol. 122, no. 1, pp. 42-44, 2011.

[6] R. Shaco-Levy, S. M. Bean, R. T. Vollmer et al., "Paget disease of the vulva: a histologic study of 56 cases correlating pathologic features and disease course," International Journal of Gynecological Pathology, vol. 29, no. 1, pp. 69-78, 2010.

[7] J. Fanning, H. C. L. Lambert, T. M. Hale, P. C. Morris, and C. Schuerch, "Paget's disease of the vulva: prevalence of associated vulvar adenocarcinoma, invasive Paget's disease, and recurrence after surgical excision," American Journal of Obstetrics and Gynecology, vol. 180, no. 1, pp. 24-27, 1999.

[8] J. J. Chanda, "Extramammary Paget's disease: prognosis and relationship to internal malignancy," Journal of the American Academy of Dermatology, vol. 13, no. 6, pp. 1009-1014, 1985.

[9] G. Marucci, C. M. Betts, R. Golouh, J. Peterse, M. P. Foschini, and V. Eusebi, "Toker cells are probably precursors of Paget cell carcinoma: a morphological and ultrastructural description," Virchows Archiv, vol. 441, no. 2, pp. 117-123, 2002.

[10] J. H. Willman, L. E. Golitz, and J. E. Fitzpatrick, "Vulvar clear cells of Toker: precursors of extramammary Paget's disease," American Journal of Dermatopathology, vol. 27, no. 3, pp. 185188, 2005.

[11] M. D. Lagios, P. R. Westdahl, M. R. Rose, and S. Concannon, "Paget's disease of the nipple. Alternative management in cases without or with minimal extent of underlying breast carcinoma," Cancer, vol. 54, no. 3, pp. 545-551, 1984.

[12] P. E. Ellis, A. B. MacLean, L. F. Wong Te Fong, J. C. Crow, and C. W. Perrett, "Angiogenesis in Paget's disease of the vulva and the breast: correlation with microvessel density," Journal of Oncology, vol. 2012, Article ID Article number651507, 6 pages, 2012.

[13] N. Hatta, M. Yamada, T. Hirano, A. Fujimoto, and R. Morita, "Extramammary Paget's disease: treatment, prognostic factors and outcome in 76 patients," British Journal of Dermatology, vol. 158, no. 2, pp. 313-318, 2008.
[14] V. Shepherd, E. J. Davidson, and J. Davies-Humphreys, "Extramammary Paget's disease," BJOG, vol. 112, no. 3, pp. 273-279, 2005.

[15] E. J. Wilkinson and H. M. Brown, "Vulvar Paget disease of urothelial origin: a report of three cases and a proposed classification of vulvar Paget disease," Human Pathology, vol. 33, no. 5, pp. 549-554, 2002.

[16] M. A. Nowak, P. Guerriere-Kovach, A. Pathan, T. E. Campbell, and L. M. Deppisch, "Perianal Paget's disease: distinguishing primary and secondary lesions using immunohistochemical studies including gross cystic disease fluid protein-15 and cytokeratin 20 expression," Archives of Pathology and Laboratory Medicine, vol. 122, no. 12, pp. 1077-1081, 1998.

[17] J. M. Abide, F. Nahai, and R. G. Bennett, "The meaning of surgical margins," Plastic and Reconstructive Surgery, vol. 73, no. 3, pp. 492-497, 1984.

[18] S. Kodama, T. Kaneko, M. Saito, N. Yoshiya, S. Honma, and K. Tanaka, "A clinicopathologic study of 30 patients with Paget's disease of the vulva," Gynecologic Oncology, vol. 56, no. 1, pp. 63-70, 1995.

[19] R. Shaco-Levy, S. M. Bean, R. T. Vollmer et al., "Paget disease of the vulva: a study of 56 cases," European Journal of Obstetrics Gynecology and Reproductive Biology, vol. 149, no. 1, pp. 8691, 2010.

[20] H. Baehrendtz, N. Einhorn, F. Pettersson, and C. Silfversward, "Paget's disease of the vulva: the Radiumhemmet series 19751990," International Journal of Gynecological Cancer, vol. 4, no. 1, pp. 1-6, 1994.

[21] L. P. Parker, J. R. Parker, D. Bodurka-Bevers et al., "Paget's disease of the vulva: pathology, pattern of involvement, and prognosis," Gynecologic Oncology, vol. 77, no. 1, pp. 183-189, 2000.

[22] S. Tebes, R. Cardosi, and M. Hoffman, "Paget's disease of the vulva," American Journal of Obstetrics and Gynecology, vol. 187, no. 2, pp. 281-284, 2002.

[23] D. Crawford, M. Nimmo, P. B. Clement et al., "Prognostic factors in Paget's disease of the vulva: a study of 21 cases," International Journal of Gynecological Pathology, vol. 18, no. 4, pp. 351-359, 1999.

[24] D. Black, C. Tornos, R. A. Soslow, C. S. Awtrey, R. R. Barakat, and D. S. Chi, "The outcomes of patients with positive margins after excision for intraepithelial Paget's disease of the vulva," Gynecologic Oncology, vol. 104, no. 3, pp. 547-550, 2007.

[25] C. Anton, A. V. C. Luiz, F. M. Carvalho, E. C. Baracat, and J. P. Carvalho, "Clinical treatment of vulvar paget's disease: a case report," Clinics, vol. 66, no. 6, pp. 1109-1111, 2011.

[26] B. Yanes, M. Notter, and D. Dragusanu, "Place de la radiothérapie dans la prise en charge de la maladie de paget extra-mammaire," Cancer Radiothérapie, vol. 11, pp. 382-430, 2007.

[27] J. P. E. N. Pierie, U. Choudry, A. Muzikansky, D. M. Finkelstein, and M. J. Ott, "Prognosis and management of extramammary Paget's disease and the association with secondary malignancies," Journal of the American College of Surgeons, vol. 196, no. 1, pp. 45-50, 2003.

[28] P. Besa, T. A. Rich, L. Delclos, C. L. Edwards, D. M. Ota, and J. T. Wharton, "Extramammary Paget's disease of the perineal skin: role of radiotherapy," International Journal of Radiation Oncology Biology Physics, vol. 23, no. 7, pp. 73-78, 1992.

[29] B. H. Valentine, B. Arena, and E. Green, "Laser ablation of recurrent Paget's disease of vulva and perineum," Journal of Gynecologic Surgery, vol. 8, no. 1, pp. 21-24, 1992. 
[30] T. L. Ewing, "Paget's disease of the vulva treated by combined surgery and laser," Gynecologic Oncology, vol. 43, no. 2, pp. 137-140, 1991.

[31] C. Louis-Sylvestre, B. Haddad, and B. J. Paniel, "Paget's disease of the vulva: results of different conservative treatments," European Journal of Obstetrics Gynecology and Reproductive Biology, vol. 99, no. 2, pp. 253-255, 2001.

[32] E. Clément, A. Sparsa, V. Doffoel-Hantz et al., "Traitement de la maldie de paget extramammaire par photothérapie dynamique topique," Annales de Dermatologie et de Vénéréologie, vol. 139, pp. 103-108, 2012.

[33] A. Karam, J. S. Berek, A. Stenson, J. Rao, and O. Dorigo, "HER2/neu targeting for recurrent vulvar Paget's disease. A case report and literature review," Gynecologic Oncology, vol. 111, no. 3, pp. 568-571, 2008. 


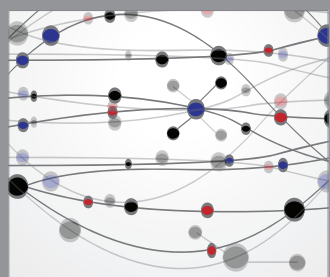

The Scientific World Journal
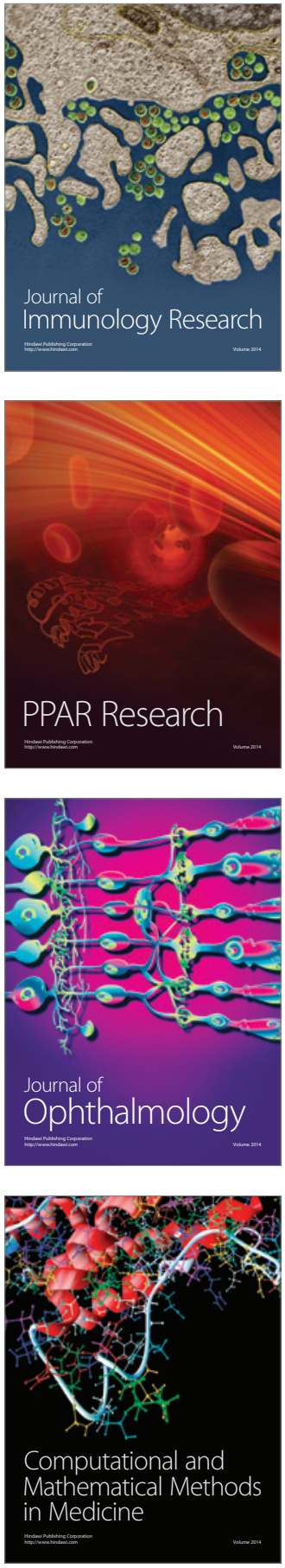

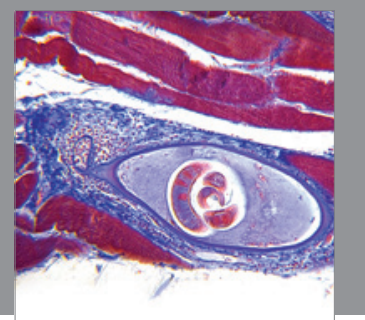

Gastroenterology

Research and Practice
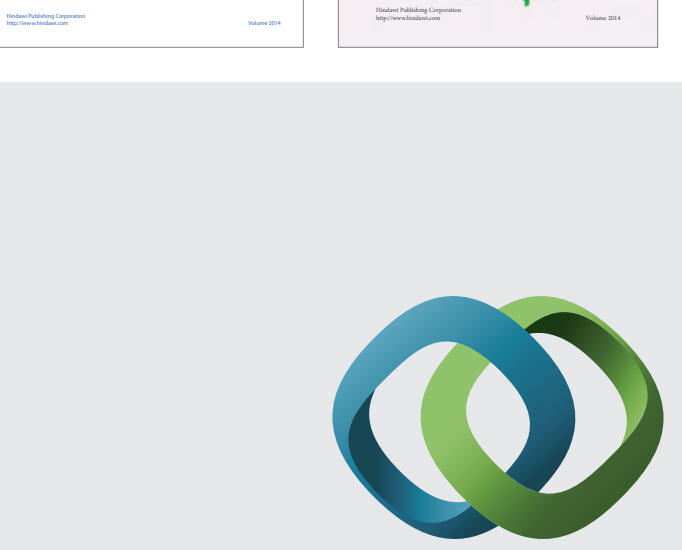

\section{Hindawi}

Submit your manuscripts at

http://www.hindawi.com
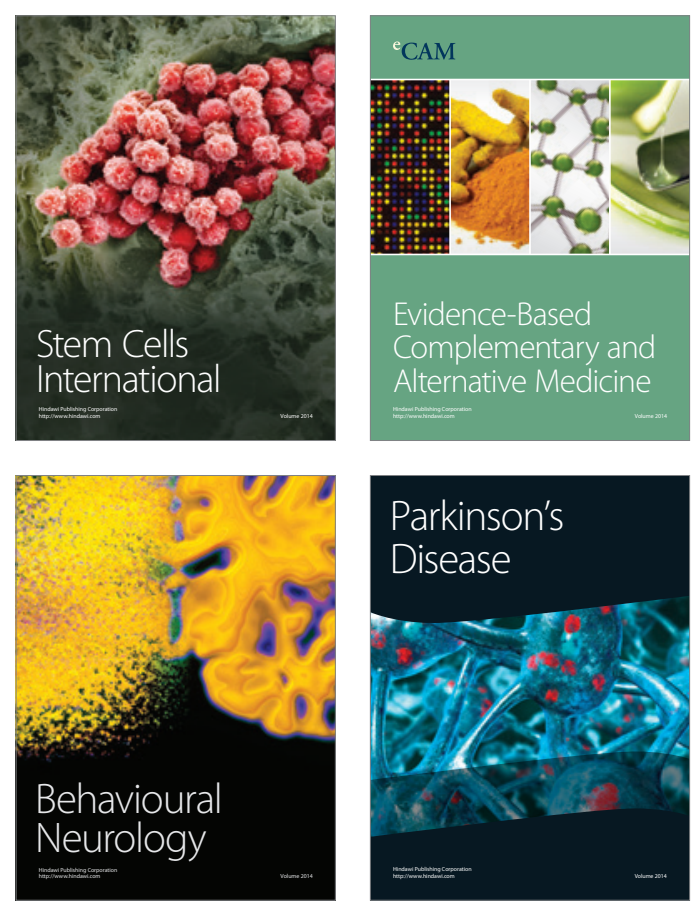

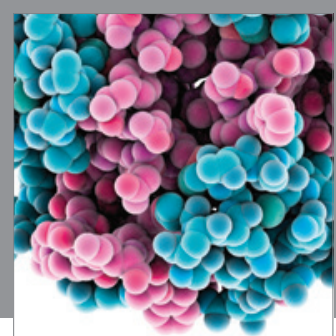

Journal of
Diabetes Research

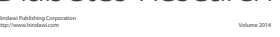

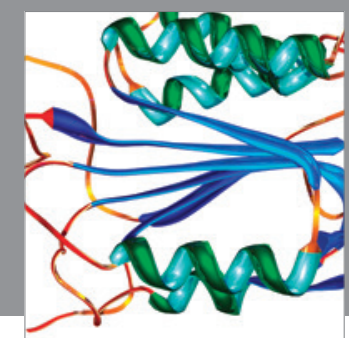

Disease Markers
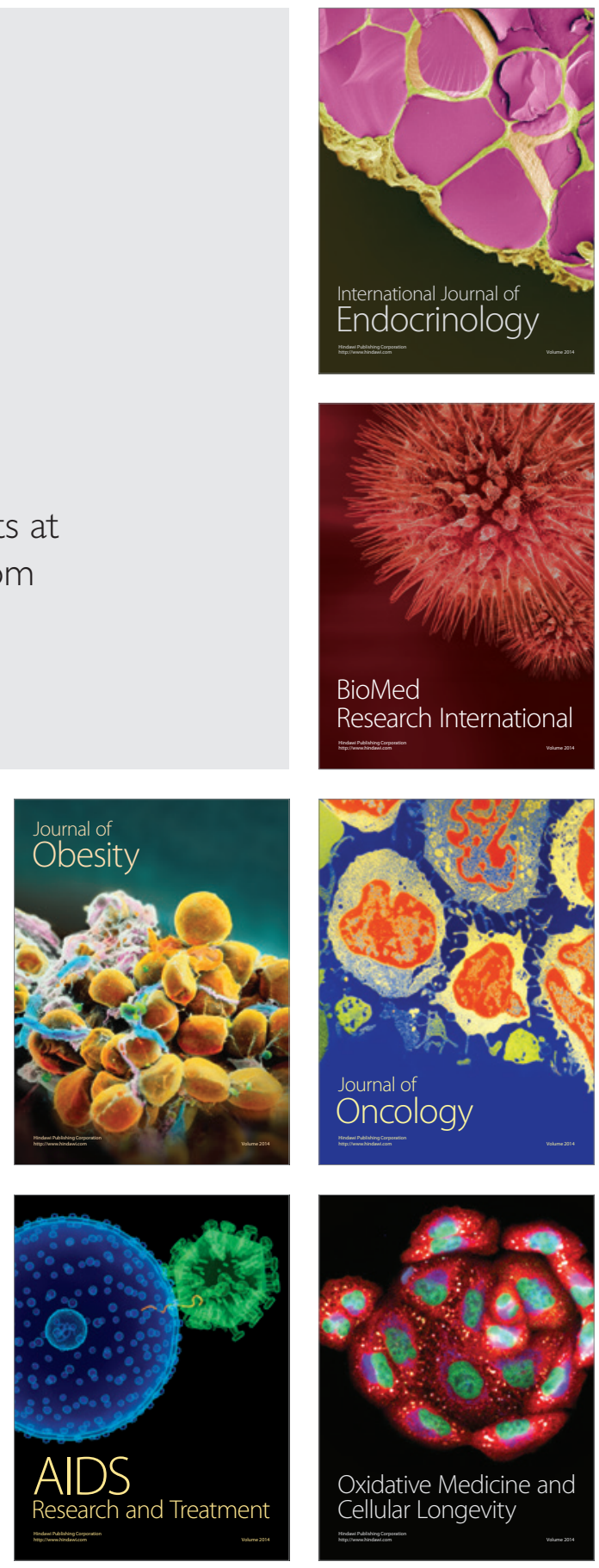